\title{
Cell biology of copper
}

\author{
Valeria Culotta
}

Published online: 31 October 2009

(C) SBIC 2009

Copper is clearly an important element in biology with approximately 30 enzymes having been shown to utilize copper as a cofactor. Although this number may be dwarfed by those for zinc and iron, the reactivity of copper with oxygen has made this transition metal particularly important for cellular redox reactions. It is noteworthy that the same redox and coordination chemistry that makes copper an ideal enzymatic cofactor also makes this element deleterious. At certain doses, copper is toxic to all life forms, and the toxicity mechanisms range from oxidative damage to inappropriate binding with sulfur, oxygen, and imidazole ligands in the cell. To balance the beneficial and deleterious effects of copper, cells have evolved with a number of homeostatic processes that ensure adequate uptake and distribution of the metal, while detoxifying the metal as needed. This special issue of Journal of Biological Inorganic Chemistry is dedicated to providing some of the latest advances in our understanding of copper in biology. Through various reviews and original research articles, a broad perspective on copper cell biology is provided ranging from bioinorganic to evolutionary biology viewpoints, to the role of copper in disease.

One important means for copper acquisition in eukaryotes is through the high-affinity copper transporter CTR1. This transporter, originally identified through yeast genetics, is well conserved throughout fungi, plants, and

This article will be printed in the upcoming Journal of Biological Inorganic Chemistry special issue Cell Biology of Copper.

V. Culotta $(\square)$

Environmental Health Sciences,

Johns Hopkins Bloomberg School of Public Health,

615 N. Wolfe Street,

Baltimore, MD 21205, USA

e-mail:vculotta@jhsph.edu animals. In an original research article by Hua et al. [1], a Drosophila model system is used to examine the requirement for fly CTR1 and human CTR1 in animal development in comparison with their roles in accumulation of toxic copper. Plants express a family of CTR1-like transporters known as COPT, and Peñarrubia et al. [2] review the distribution and function of these transporters in plants with special emphasis on their regulation by copper-controlled microRNAs.

Another important participant in copper homeostasis is the well-conserved family of copper-transporting ATPases present in both bacteria and eukaryotes. Depending on the organism or cell type, $\mathrm{Cu}$-ATPases function in copper uptake, efflux, or intracellular partitioning of the metal. In a review by Barry et al. [3], the structural organization of $\mathrm{Cu}$-ATPases is surveyed from an evolutionarily viewpoint extending from bacteria to humans. An intriguing comparison between bacterial and eukaryotic $\mathrm{Cu}$-ATPases is provided in a review by Solioz et al. [4]. Surprisingly, not all organisms require copper for life and in certain Grampositive bacteria, copper is only toxic, not essential. Solioz et al. [4] describe how the $\mathrm{Cu}$-ATPases in these organisms have solely evolved to detoxify copper by exporting it from the cell. By comparison, eukaryotic $\mathrm{Cu}$-ATPases have a function in both accumulation of essential copper and efflux of the toxic metal and are subject to complex modes of regulation. Van den Berghe and Klomp [5] provide a comprehensive review of how eukaryotic $\mathrm{Cu}$-ATPases are regulated by changes in copper availability and other forms of cell stress and by hormonal signals.

$\mathrm{Cu}$-ATPases can acquire copper through the action of a small copper chaperone, known as Atx1 (photosynthetic bacteria and yeast) or Atox1 (mammals). In an original research article, Dainty et al. [6] provide evidence that Synechocystis Atx1 can also participate in zinc buffering 
and can impinge on zinc regulation of the zinc-transporting ATPase ZiaA. This Zn-ATPase bears striking homology to the $\mathrm{Cu}$-ATPase of the same organism, yet only the latter can physically interact with Atx1. The mechanism is probed in a second research paper, by Robinson in close collaboration with Bertini's group [7], where the solution structure of the zinc binding domain of ZiaA is solved, revealing the nature of the specificity for Atx1 interactions. The role of eukaryotic Atox1 in subcellular copper distribution is investigated in a research article by McRae et al. [8]. By using state-of-the-art quantitative synchrotron X-ray fluorescence microscopy imaging, McRae et al. [8] examined the effects of Atox 1 gene deletions on copper distribution and document a role for Atox 1 in maintaining proper subcellular organization of the metal in mammalian cells.

One class of enzymes that receive copper through the Atx1-Cu-ATPase delivery system is the multicopper oxidases (MCO). MCOs are unique among copper proteins in that they can contain three distinct copper sites: type 1, type 2 , and the binuclear type 3 . In a comprehensive review by Kosman [9], the evolutionary biology, coordination chemistry, and physiological functions of MCOs are discussed.

With the essential and potentially toxic nature of copper, it is not surprising that disruptions in copper homeostasis can lead to disease. As introduced in the review by van den Berghe and Klomp [5], mutations in the human $\mathrm{Cu}$-ATPases (known as ATP7A and ATP7B) are associated with severe disorders of copper metabolism. Specifically ATP7A is mutated in the fatal X-linked neurodevelopmental disorder Menkes disease and ATP7B mutations are associated with the hepatolenticular copper-overload disorder, Wilson disease. The central nervous system is particularly vulner- able to changes in copper availability, and in a review by Hung et al. [10] the effects of copper on the brain are described with emphasis on Alzheimer disease.

All together, this compilation of reviews and research articles represents an important sampling of the current thinking on copper cell biology. By combining bioinorganic and evolutionary biology perspectives with translational aspects of copper in disease, these reports are likely to stimulate new ideas and directions for exploring the impact of copper in biology and health.

\section{References}

1. Hua H, Georgiev O, Schaffner W, Steiger D (2010) J Biol Inorg Chem. doi:10.1007/s00775-009-0599-0

2. Peñarrubia L, Andrés-Colás N, Moreno J, Puig S (2010) J Biol Inorg Chem. doi:10.1007/s00775-009-0591-8

3. Barry AN, Shinde U, Lutsenko S (2010) J Biol Inorg Chem. doi: 10.1007/s00775-009-0595-4

4. Solioz M, Abicht HK, Mermod M, Mancini S (2010) J Biol Inorg Chem. doi:10.1007/s00775-009-0588-3

5. van den Berghe PVE, Klomp LWJ (2010) J Biol Inorg Chem. doi: 10.1007/s00775-009-0592-7

6. Dainty SJ, Patterson CJ, Waldron KJ, Robinson NJ (2010) J Biol Inorg Chem. doi:10.1007/s00775-009-0555-Z

7. Banci L, Bertini I, Ciofi S, Poggi L, Vanarotii M, Tottey S, Waldron KJ, Robinson NJ (2010) J Biol Inorg Chem. doi: 10.1007/s00775-009-568-7

8. McRae R, Lai B Fahrni CJ (2010) J Biol Inorg Chem. doi: 10.1007/s00775-009-0598-1

9. Kosman DJ (2010) J Biol Inorg Chem. doi:10.1007/s00775009-0590-9

10. Hung YH, Bush AI, Cherney RA (2010) J Biol Inorg Chem. doi: 10.1007/s00775-009-0600-y 